\title{
Functional Consequences of Compartmentalization of Synaptic Input
}

\author{
Melissa J. Coleman and Michael P. Nusbaum \\ Neurobiology Research Center and Department of Physiology and Biophysics, University of Alabama at Birmingham, \\ Birmingham, Alabama 35294-0021
}

\begin{abstract}
Intra-axonal recordings of stomatogastric nerve axon 1 (SNAX1) indicate that there are synaptic inputs onto the SNAX1 terminals in the stomatogastric ganglion (STG) of the crab Cancer borealis (Nusbaum et al., 1992b). To determine whether this synaptic input only influenced SNAX1 activity within the STG, we identified the SNAX1 soma in the commissural ganglion (CoG). We found that this neuron has a neuropilar arborization in the CoG and also receives synaptic inputs in this ganglion. Based on its soma location, we have renamed this neuron modulatory commissural neuron 1 (MCN1). While intracellular stimulation of MCN1 $1_{\text {soma }}$ and MCN $_{\text {SNAx }}$ has the same excitatory effects on the STG motor patterns, MCN1 receives distinct synaptic inputs in the STG and CoG. Moreover, the synaptic input that MCN1 receives within the STG compartmentalizes its activity. Specifically, the lateral gastric (LG) neuron synaptically inhibits $\mathrm{MCN}_{\text {SNAX}^{-}}$ initiated activity within the STG (Nusbaum et al., 1992b), and while LG did not inhibit MCN1 some-initiated activity in the CoG, it did inhibit these MCN1 impulses when they arrived in the STG. As a result, during $\mathrm{MCN1}_{\text {soma-elicited gastric mill }}$ rhythms, MCN1 $1_{\text {soma }}$ is continually active in the CoG but its effects are rhythmically inhibited in the STG by LG neuron impulse bursts. One functional consequence of this local control of MCN1 within the STG is that the LG neuron thereby controls the timing of the impulse bursts in other gastric mill neurons. Thus, local synaptic input can functionally compartmentalize the activity of a neuron with arbors in distinct regions of the nervous system.
\end{abstract}

[Key words: crab, neuromodulation, presynaptic inhibition, projection neuron, rhythmic motor patterns, stomatogastric ganglion, synaptic compartmentalization]

Neurons often project long distances to influence their targets. Such is the case for many neurons that influence rhythmically active neural networks (Brodfuehrer and Freisen, 1986a; McCrohan, 1988; Grillner and Matsushima, 1991; Harris-Warrick et al., 1992b; Perreault et al., 1993; Rudomin et al., 1993).

\footnotetext{
Received Jan. 21, 1994; revised Apr. 26, 1994; accepted Apr. 27, 1994.

This research was supported by U.S. Public Health Service Grant NS29436 (M.P.N.) and by the Human Frontiers Science Program. We thank Andrew Christia for assistance in producing the confocal image of $\mathrm{MCN}_{\text {soma }}$, and Larry Abbott, Dawn Blitz, Pierre Meyrand, and Brian Norris for helpful discussions and comments on earlier versions of the manuscript. Some of this work was performed at the Marine Biological Laboratory, Woods Hole, MA.

Correspondence should be addressed to Dr. Michael P. Nusbaum, Department of Neuroscience, University of Pennsylvania School of Medicine, 215 Stemmler Hall, Philadelphia, PA 19104-6074.

aPresent address: Department of Neuroscience, University of Pennsylvania School of Medicine, 215 Stemmler Hall, Philadelphia, PA 19104-6074.

Copyright (C) 1994 Society for Neuroscience $0270-6474 / 94 / 146544-09 \$ 05.00 / 0$
}

Intracellular recordings from the somata of these projection neurons has provided considerable information regarding their influence on neural network activity. However, the release sites at which they influence their network targets are electrotonically distant from the soma recording site, providing little information regarding the activity occurring at these distant terminals.

Projection neurons may well be influenced at their distant terminals, since there is considerable evidence for presynaptic influences in the nervous system (Glantz et al., 1985; Brodfuehrer and Friesen, 1986b; Clarac et al., 1992; Nusbaum et al., 1992b; Watson, 1992). Such presynaptic influences provide for the possibility that these neurons could be functionally compartmentalized. Functional compartmentalization of neuronal activity has been addressed in several systems (Nelson et al., 1975; Nagy et al., 1981; Haydon and Winlow, 1982; Oland et al., 1987; Ross et al., 1990; Hounsgaard and Kiehn, 1993; Skydsgaard and Hounsgaard, 1994). However, the consequences of this compartmentalization for the targets of these neurons remain to be determined in most systems.

One system in which the functional consequences of neuronal compartmentalization can be addressed is the stomatogastric nervous system (STNS) of decapod crustaceans (Selverston and Moulins, 1987; Harris-Warrick et al., 1992a). The STNS produces several rhythmically active motor patterns, including the pyloric and gastric mill rhythms. These two rhythms are produced by a neural network whose component neurons are located within the stomatogastric ganglion (STG), and which is strongly influenced by modulatory inputs from more anterior ganglia (Coleman et al., 1992, 1993; Harris-Warrick et al., 1992b; Marder and Weimann, 1992; Nusbaum et al., 1992a; Norris et al., 1993).

To examine the events occurring at the STG terminals of these projection neurons, Nusbaum et al. (1992b) recorded intra-axonally, at the entrance to the STG, from an identified modulatory neuron in the crab Cancer borealis. They reported that this neuron, called stomatogastric nerve axon 1 (SNAX1), arborizes throughout the STG neuropil, excites the STG network, and also receives synaptic inputs within the STG. Specifically, SNAX 1 is electrically coupled to the lateral gastric (LG) neuron and it also receives inhibitory postsynaptic potentials (IPSPs) from ICG that are strong enough to inhibit action potentials elicited in SNAX1.

We wanted to determine whether the synaptic inhibition of the SNAX1 terminals by LG only influenced SNAX1 activity within the STG, without affecting its activity in the CoG. We report here the identification of the SNAX1 soma in the CoG, and that this neuron has an arborization within the $\mathrm{CoG}$ onto which it receives synaptic inputs. We have therefore renamed this neuron modulatory commissural neuron 1 (MCN1). To 
simplify the nomenclature regarding the two $\mathrm{MCN} 1$ recording sites, we label intrasomatic recordings " $\mathrm{MCN} 1_{\text {soma }}$ ", and intraaxonal recordings of SNAX1 "MCN1 $1_{\text {SNAX. }}$. By performing simultancous intracellular recordings from these two sites, we found that $\mathrm{MCN} 1$ receives distinct synaptic inputs in the STG and $\mathrm{CoG}$. Moreover, we found that the inhibitory input from the LG neuron onto $\mathrm{MCN} 1_{\mathrm{SNAx}}$ only locally influences $\mathrm{MCN} 1$ activity, causing this neuron to have different activity patterns in the $\mathrm{CoG}$ and STG. A functional consequence of this local inhibition is that, by regulating the timing of the MCNl excitatory effects onto its STG neuron targets, the LG neuron controls the timing of the impulse bursts in other STG neurons during MCN1-elicited gastric mill rhythms.

Some of these data appeared previously in abstract form (Coleman and Nusbaum, 1992).

\section{Materials and Methods}

Animals. Adult male Cancer borealis were obtained from Neptune Lobster and Seafood Company (Boston, MA), and the Marine Biological Laboratory (Woods Hole, MA) and were maintained in circulating, aerated artificial or natural seawater $\left(10-13^{\circ} \mathrm{C}\right)$ until used. Crabs were cold anesthetized by packing in ice for $20-40$ min prior to dissection. Data were obtained from a total of 88 animals.

Solutions. $C$. borealis physiological saline contained (mM) $\mathrm{NaCl}, 440$ $\mathrm{KCl}, 11 ; \mathrm{MgCl}_{2}, 26 ; \mathrm{CaCl}_{2}, 13$; Trizma base, 10; and maleic acid, 5 (pH 7.4-7.5). Proctolin was obtained from Sigma Chemical Co. (St. Louis, MO). Locustatachykinin I and II were obtained from Peninsula Labs (Belmont, CA). These peptides were stored as frozen aliquots of stock solution $\left(10^{-2} \mathrm{M}\right.$ or $\left.10^{-3} \mathrm{M}\right)$ and were diluted to the final working concentration in saline immediately before they were used.

Electrophysiology. The stomatogastric nervous system was dissected from the crab stomach and pinned to a saline-filled, Sylgard (Dow Corning)-lined petri dish. The STNS consists of four ganglia plus their connecting and motor nerves. The four ganglia include the paired CoGs, the unpaired esophageal ganglion (OG), and the unpaired STG (Fig. 1). To facilitate intracellular recordings, the STG and CoGs were desheathed and viewed with white light transmitted through a dark-field condensor (Nikon). Individual STG neurons were identified by their axonal pathways, activity patterns, and their interactions with other neurons (Weimann et al., 1991, 1993; Nusbaum et al., 1992b). Preparations were superfused continuously $(7-12 \mathrm{ml} / \mathrm{min})$ with physiological saline cooled to $10-13^{\circ} \mathrm{C}$. Intracellular and extracellular recordings were made using routine methods for the STNS (Selverston and Moulins, 1987). Intracellular recordings were made with microelectrodes (15-30 $\mathrm{M \Omega}$ ) that were filled with $4 \mathrm{M}$ potassium acetate plus $20 \mathrm{mM} \mathrm{KCl}$. Extracellular recordings were made using stainless steel wire electrodes that were pressed into the Sylgard alongside individual nerves and isolated from the bath by Vaseline. Data were collected directly onto chart recorder paper (Astromed MT-95000) and stored on videotape (Vetter Instruments). Figures were prepared by scanning data into a graphics program (CORELDRAw, version 3.0) using Scanjet IIc (Hewlett Packard).

To block action potential propagation reversibly through the superior esophageal nerves (sons; Fig. 1), the sons were desheathed and a Vaseline well was placed around the desheathed area. Impulse propagation was blocked by replacing the saline in the well with an isotonic sucrose solution $(750 \mathrm{~mm})$. The impulse propagation block was effectively reversed by replacing the sucrose with saline. In order to superfuse neuropeptides selectively onto the STG, this ganglion was isolated from the CoGs and OG by a Vaseline wall built across the middle of the sin. In these experiments, separate superfusion lines and switching manifolds were used for each half of the preparation.

Lucifer yellow dye fills and immunocytochemistry. Intracellular Lucifer yellow (LY-CH; Sigma) dye fills were accomplished using microelectrodes $(40-80 \mathrm{M} \Omega)$ whose tips were filled with $5 \% \mathrm{LY}$ in water. The electrode shaft was filled with $1 \mathrm{M} \mathrm{LiCl}$, with an air bubble separating the two solutions. LY iontophoresis, and subsequent processing for visualization, followed the techniques in Nusbaum et al. (1992b). In some preparations, the signal from the LY-fill was amplified using a polyclonal anti-LY antiserum (gift of J. Y. Kuwada, Department of Biology, University of Michigan). Processing for LY immunolabeling in whole-mounts followed the techniques of Beltz and Kravitz (1983),

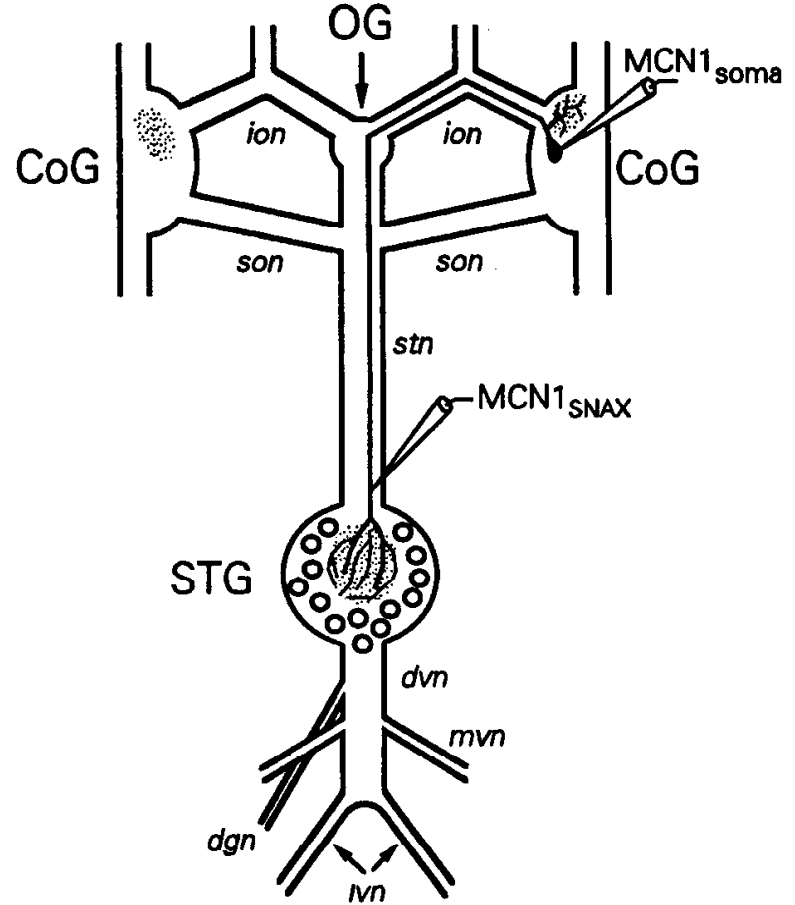

Figure 1. Schematic diagram of the stomatogastric nervous system, including the modulatory commissural neuron $1(M C N I)$ projection pattern. Although not illustrated, there is also an $\mathrm{MCN} 1$ in the contralateral commissural ganglion (CoG). The schematized microelectrodes represent the two $\mathrm{MCN} 1$ recording sites. The stippled region in the CoGs and stomatogastric ganglion (STG) represents neuropil. dgn, dorsal gastric nerve; $d v n$, dorsal ventricular nerve; ion, inferior esophageal nerve $l v n$, lateral ventricular nerve; $m v n$, medial ventricular nerve; $O G$, esophageal ganglion; son, superior esophageal nerve; stn, stomatogastric nerve.

as modified by Marder et al. (1986) and Coleman et al. (1992). The anti-LY antiserum was used at a final dilution of 1:2000, and was visualized using FITC-conjugated goat anti-rabbit antiserum (Calbiochem, La Jolla, CA) at a final dilution of 1:25. In some preparations, we used laser scanning confocal microscopy to acquire images of $\mathrm{MCN} 1_{\text {soma }}$ that could be combined to include all of the CoG branches of the LY-filled MCN1, as well as the soma, in a single focal plane. Briefly, a Bio-Rad MRC 600 laser scanning confocal microscope, equipped with a krypton/argon mixed gas laser, was used. Low-magnification optical sections (2.0-4.0 $\mu \mathrm{m}$ thickness) of the CoG neuropil were collected, and composite images were produced by combining the individual images.

\section{Results}

\section{$M C N 1_{\text {soma }}$ identification}

Previously, we used anatomical techniques to show that most of the inputs to the crab STG originate from somata in the paired CoGs, and that only two or three of these somata project through the inferior esophageal nerve (ion) to reach the STG (Coleman et al., 1992). Nusbaum et al. (1992b) showed, electrophysiologically, that $\mathrm{MCNI}_{\mathrm{SNAx}}$ projected through the $s t n$ and ion into the CoG (Fig. 1). Using our anatomical localization of the $\mathrm{CoG}$ neurons as a guide, we identified the soma of $\mathrm{MCN1}_{\mathrm{SNAX}}$, electrophysiologically. $\mathrm{MCN} 1_{\text {soma }}$ was commonly found on the dorsal surface of the $\mathrm{CoG}$, anterior to the previously identified L neuron (Robertson and Moulins, 1981), which has the largest soma in the CoG. The MCN1 soma is approximately $45 \mu \mathrm{m}$ in diameter. There appears to be only one MCN1 in each $\mathrm{CoG}$, since in recordings from approximately $65 \mathrm{CoGs}$ we never found more than one MCNl per ganglion. 


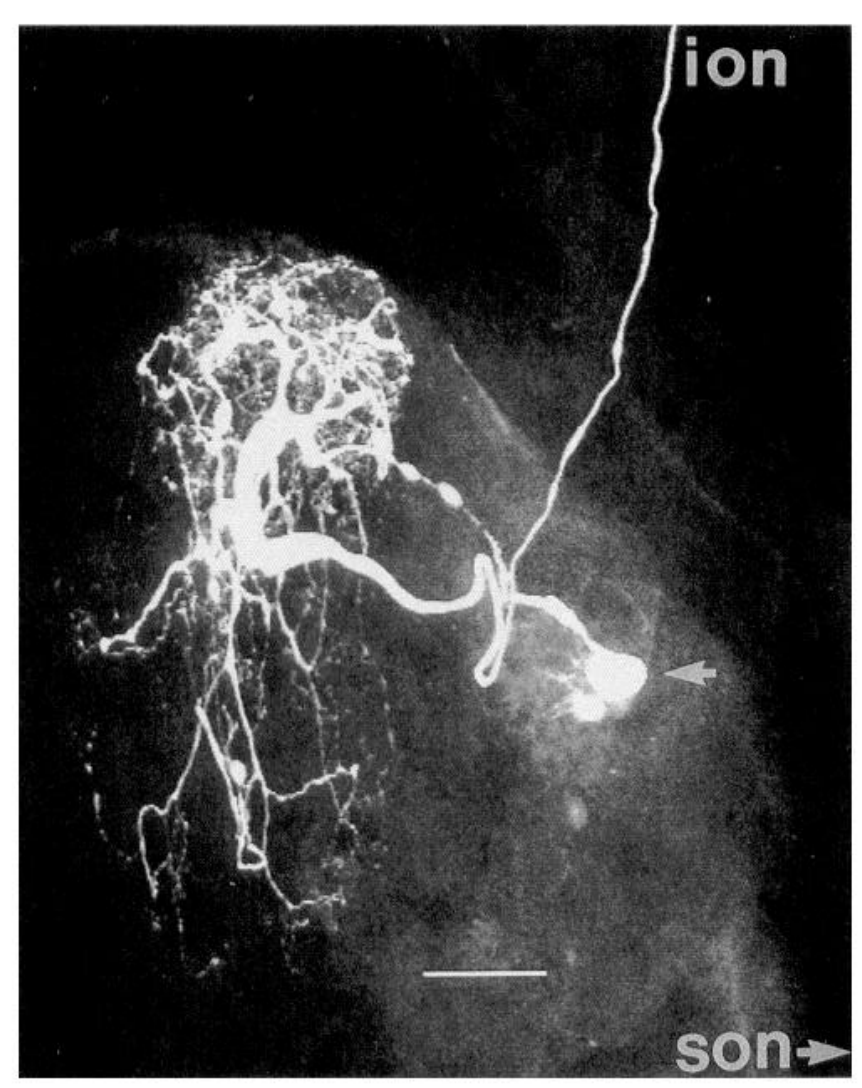

Figure 2. Confocal image of an intracellular Lucifer yellow dye fill of $\mathrm{MCN}_{\text {soma }}$, in whole-mount. A relatively thin neurite connects the MCN1 soma (arrow) with an expanded neurite within the neuropil. The CoG neuropil branches of $\mathrm{MCN} 1$ all originate from this expanded neurite. MCN1 projects from the $\mathrm{CoG}$ through the ion (upper right). The son is at the lower right. The small bleb alongside the MCN1 soma resulted from damage to the soma during removal of the intracellular electrode. The Lucifer yellow dye fill was intensified by processing the preparation with anti-Lucifer yellow antiserum, visualized with a fluorescein-conjugated secondary antiserum (see Materials and Methods). Scale bar, $100 \mu \mathrm{m}$.

Nusbaum et al. (1992b) showed that MCN1 has an arborization within the STG (Fig. 1). We found that each dye-filled MCN1 also had an arborization within its own CoG (Fig. 2). The branching pattern of $\mathrm{MCN} 1$ within the $\mathrm{CoG}$ routinely included a small-diameter neurite that extended from the MCN1 soma into the neuropil (Fig. 2). Within the neuropil, this thin neurite expanded considerably in diameter. All of the fine neuropil branches of $\mathrm{MCN} 1$ within the $\mathrm{CoG}$ originated from this expanded region. These fine branches were distributed throughout the dorsoventral extent of the anterior neuropil. As the main neurite approached the ion, it decreased in diameter.

Like $\mathrm{MCN1}_{\text {SNAX }}, \mathrm{MCN1}_{\text {soma }}$ projected through the ion and stn to reach the STG. As shown by the simultaneous intracellular recordings from $\mathrm{MCN1}_{\mathrm{SNAx}}$ and $\mathrm{MCN1}_{\text {soma }}$ in Figure 3, each action potential triggered at either $\mathrm{MCN1}_{\mathrm{SNAx}}$ or $\mathrm{MCN1}_{\text {soma }}$ was recorded extracellularly in the stn and ion, and then intracellularly at the other recording site. The latency from one intracellular recording site to the other was approximately $26 \mathrm{msec}$. As a further confirmation that the $\mathrm{MCN1}_{\text {soma }}$ and $\mathrm{MCN1}_{\mathrm{SNAX}}$ recordings were of the same neuron, in one preparation we performed collision experiments between impulses initiated at the $\mathrm{MCN}_{\text {soma }}$ and $\mathrm{MCNl}_{\text {SNAx }}$ sites. When impulses were initiated at both of these sites within $20 \mathrm{msec}$ of one another, the
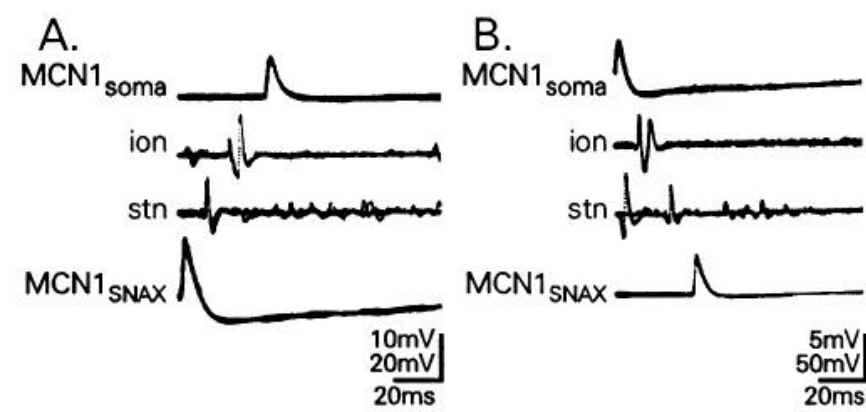

Figure 3. Superimposed oscilloscope sweeps showing that $\mathrm{MCN}_{\text {soma }}$ and $\mathrm{MCN1}_{\mathrm{SNAX}}$ have the same projection within the stomatogastric nervous system, and cause time-locked action potentials in each other. $A$, Each action potential elicited in $\mathrm{MCN} 1_{\text {SNAx }}$ produced constant-latency action potentials in the $s t n$, ion, and $\mathrm{MCN1}_{\text {soma }}$. B. Each action potential elicited in $\mathrm{MCN1}_{\text {soma }}$ is followed by fixed latency action potentials in the ion, stn, and $\mathrm{MCNl}_{\mathrm{SNAx}} A$ and $B$ are from the same recordings.

two impulses collided at a location in between the extracellular recording sites in the ion and stn. As a result, the $\mathrm{MCN}_{\text {soma }}$ impulse was recorded only in the ion and the $\mathrm{MCN}_{\mathrm{SNAX}}$ impulse was recorded only in the $s t n$. The location as well as the occurrence of the collision could be changed by altering the delay between initiation of the two impulses. We found no indication from either dye fills or electrophysiological recordings that $\mathrm{MCN} 1$ projected to the contralateral $\mathrm{CoG}$.

There was little difference between the excitatory effects of $\mathrm{MCN}_{\text {SNAX }}$ and $\mathrm{MCN}_{\text {soma }}$ on the pyloric and gastric mill motor patterns in the STG. For example, as shown in Figure 4, $\mathrm{MCNl}_{\text {soma }}$ activation caused an increase in the pyloric cycle frequency and also initiated a gastric mill rhythm. Similar results were shown for activation of $\mathrm{MCN}_{\mathrm{SNAX}}$ (Nusbaum et al., 1992b). In this recording, the pyloric rhythm was monitored with an extracellular recording of the pyloric dilator nerve $(p d n)$, in which the activity of the two pyloric dilator (PD) neurons is selectively recorded. These neurons are members of the pyloric motor pattern pacemaker group (Selverston and Moulins, 1987; Weimann et al., 1991). The $\mathrm{MCN}_{\text {soma }}$-elicited gastric mill motor pattern in Figure 4 is represented by the alternation in activity of the dorsal gastric (DG) and the coactive LG and gastric mill (GM) motor neurons. Although not shown, $\mathrm{MCN1}_{\text {soma }}$ stimulation also shared with $\mathrm{MCN1}_{\mathrm{SNAx}}$ the ability to initiate the pyloric rhythm.

\section{$M C N 1_{\text {soma }}$ and $M C N 1_{S N A X}$ receive distinct synaptic input}

Since MCN1 has an arborization in both the CoG and the STG, it was possible that this neuron received distinct synaptic inputs in the two ganglia. Nusbaum et al. (1992b) showed that $M C N 1_{\text {SNAX }}$ receives input from both pyloric and gastric mill neurons in the STG, and that during $\mathrm{MCN1}_{\mathrm{SNAx}}$ stimulation, this region of the neuron showed activity that was time locked to the STG motor patterns. This included a reduction or suppression of $\mathrm{MCN}_{\text {SNAX }}$ activity by $\mathrm{LG}$ neuron impulse bursts during the gastric mill rhythm. Interestingly, $\mathrm{MCN1}_{\text {soma }}$-initiated activity in the $\mathrm{CoG}$ was not inhibited by the LG neuron impulse bursts (Fig. 4). LG does not project to the CoGs. Nevertheless, it is evident in Figure 4 that the $\mathrm{MCN}_{\text {soma }}$-elicited activity in the $\mathrm{CoG}$ was time locked to both the pyloric and gastric mill rhythms. The pyloric timing was such that MCN1 was not active during PD neuron activity. This pyloric timing was replaced by nearly tonic activity in $\mathrm{MCN1}_{\text {soma }}$ during each 


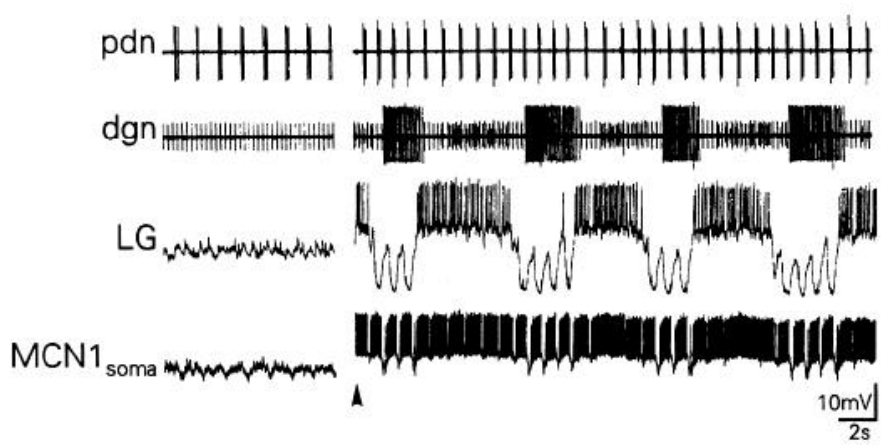

Figure 4. $\mathrm{MCN}_{\text {soma }}$ excites the pyloric rhythm and initiates a gastric mill motor pattern. Left, While $\mathrm{MCN1}_{2 \mathrm{sma}}$ was inactive, there was an ongoing pyloric rhythm (monitored with the $p d n$ recording) and no gastric mill motor pattern. The active unit in the $d g n$ is the anterior gastric receptor (AGR) neuron, a sensory neuron that is tonically active throughout both halves of the $d g n$ recording. Membrane potentials: $L G$, $-64 \mathrm{mV} ; M C N 1_{\text {sama }},-48 \mathrm{mV}$. Right, $M C N 1_{\text {soma }}$ activity (firing frequency, $28 \mathrm{~Hz}$ ) increased the pyloric rhythm frequency and elicited a gastric mill motor pattern. $M C N 1_{\text {soma }}$ activity resulted from the injection of constant-amplitude depolarizing current. Arrowhead indicates that $\mathrm{MCNl}_{\text {soma }}$ stimulation began prior to the start of this recording segment, and persisted throughout this segment. DG neuron is the largest unit in the $d g n$ recording, and the GM neurons are the smallest units in $d g n$. Membrane potential, $L G,-54 \mathrm{mV}$ to $-69 \mathrm{mV}$ (peak to trough of slow wave).

LG neuron impulse burst. Thus, while LG impulse bursts suppressed $\mathrm{MCN1}_{\text {SNAX }}$-initiated activity in the STG, it had no inhibitory influence on $\mathrm{MCN1}_{\text {soma }}$-initiated activity in the CoG.

To determine whether the rhythmic activity in $\mathrm{MCN}_{\text {soma }}$ resulted from intrinsic membrane properties, synaptic input that it received in the $\mathrm{CoG}$, or electrotonic spread from its terminals in the STG, we eliminated all STG inputs to the CoG. This was done either reversibly by placing a sucrose block on the son or irreversibly by cutting this nerve $(n=4)$. In $C$. borealis, all STG neurons that project to the CoGs do so via the sons (Coleman et al., 1992). This approach therefore enabled us to maintain the connection between $\mathrm{MCN} 1_{\text {soma }}$ and the STG, since this neuron projects to the STG via the ion (Figs. 1-3). If the pyloricand gastric mill-timed patterns in $\mathrm{MCNl}_{\text {soma }}$ resulted either from its own membrane properties or from its STG terminals, then these patterns would still be evident with impulse activity blocked in the son. As shown in Figure $5, \mathrm{MCN1}_{\text {soma }}$ activity was time locked with both the pyloric and gastric mill rhythms prior to cutting the ipsilateral son. However, after the son was cut, the rhythmic activity in $\mathrm{MCN}_{1}{ }_{\text {soma }}$ was completely eliminated, despite the persistence of the pyloric and gastric mill rhythms in the STG. Therefore, MCN1 receives both pyloric- and gastric mill-timed synaptic input in the CoG as well as in the STG.

The above experiments suggested that the synaptic inputs received by $\mathrm{MCN1}_{\text {SNAx }}$ within the STG had no influence on MCN1 within the CoG. We tested this hypothesis more directly by performing simultaneous intracellular recordings of $\mathrm{MCNl}_{\text {soma }}$ and $\mathrm{MCN}_{\text {SNAX }}$, and eliciting action potentials from either $\mathrm{MCN}_{\mathrm{SNAX}}$ (Fig. 6) or MCN1 $1_{\text {soma }}$ (Fig. 7). MCN1 has spikeinitiation zones near the CoG and at the STG (Nusbaum et al., 1992b; Fig. 7). We first asked whether the LG-mediated PSPs recorded in $\mathrm{MCN1}_{\text {SNAx }}$ could be recorded in $\mathrm{MCN}_{1} 1_{\text {soma }}$ in the $\mathrm{CoG}$, which is approximately $3 \mathrm{~cm}$ distant from the STG. As the $\mathrm{MCN1}_{\text {soma }}$ recording in Figure 4 had suggested, we found that while $\mathrm{LG}$ impulses produced IPSPs in $\mathrm{MCN1}_{\mathrm{SNAx}}$ that were strong enough to inhibit $\mathrm{MCN}_{\mathrm{SNAx}}$-elicited action potentials,

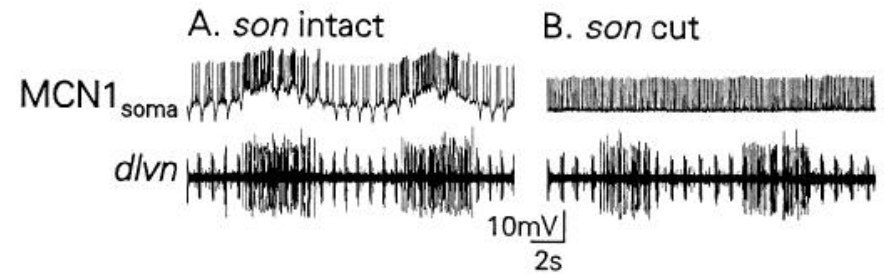

Figure 5. Pyloric- and gastric mill-timed synaptic input onto $\mathrm{MCN1}_{\text {som }}$ occurs in the CoG. $A$, With the ipsilateral son intact, $\mathrm{MCN1}_{\text {soma }}$ exhibited both pyloric- and gastric mill-timed activity. $\mathrm{MCN}_{\text {soma }}$ activity occurred without intracellular current injection. $B$, When the son was transected, $\mathrm{MCN1}_{\text {soma }}$ activity became tonic, despite the continued presence of the pyloric and gastric mill rhythms in the STG. The pyloric and gastric mill rhythms are represented by the short-duration, highfrequency bursting (PD neurons, small units) and the long-duration low-frequency bursting (GM neurons, large units) in the dlvn recording, respectively. $\mathrm{MCN1}_{\text {soma }}$ membrane potential: $A,-45 \mathrm{mV}$ to $50 \mathrm{mV}$ (peak to trough of pyloric-timed inhibition); $B,-43 \mathrm{mV}$.

there was no evidence of these IPSPs in the $\mathrm{MCN}_{\text {soma }}$ recording (Fig. 6A). Impulse activity was no longer recorded at $\mathrm{MCN}_{\text {soma }}$ during LG stimulation in Figure $6 A$ because the impulses had been originating at the STG and propagating toward the CoG. The lack of LG-mediated PSPs in $\mathrm{MCN1}_{\text {soma }}$ is also evident in Figure $6 B$, which shows a series of superimposed oscilloscope traces triggered by impulses elicited in LG. In this experiment, the contralateral $\mathrm{MCN}_{\mathrm{SNAx}}$ and $\mathrm{MCN1}_{\text {soma }}$ were recorded during LG stimulation. Each LG impulse elicited two events in $\mathrm{MCN}_{\text {SNAX }}$ including an initial depolarization that results from electrical coupling, followed by an IPSP (Nusbaum et al., 1992b). Neither of these events were recorded in $\mathrm{MCN1}_{\text {soma }}$.

Using $\mathrm{MCN}_{\text {soma }}$ recordings, we were also able to study the effects of $\mathrm{LG}$ on $\mathrm{MCN1}_{\mathrm{SNAX}}$-initiated activity without impaling and depolarizing $\mathrm{MCN1}_{\mathrm{SNAX}}$. This was possible because, in some preparations, the STG spike initiation zone of MCNl became activated following $\mathrm{MCN}_{\text {soma }}$ stimulation. This occurred despite the fact that the depolarization produced by current injection into $\mathrm{MCN} 1_{\text {soma }}$ never reached the $\mathrm{MCN} 1_{\text {SNAx }}$ recording site (see Fig. 8). Meyrand et al. (1992) showed that the same phenomenon sometimes occurs in an STG neuron following intrasomatic stimulation. The switch in the site of MCN1 spike initiation is evident in the ion recording in Figure 7, where the change in the direction of propagation of the MCN1 spikes is reflected in a change in its shape (see also Fig. 3). This switch in the site of spike initiation was confirmed using oscilloscope sweeps to observe directly the time of arrival of the MCN1 action potentials at the different intracellular and extracellular recording sites. When the STG spike initiation zone of MCN1 was active, stimulation of LG again effectively suppressed MCN1 activity at this location (Fig. 7). Once again, the LG-mediated inhibition produced no membrane potential change at the $\mathrm{MCN1}_{\text {soma }}$ recording site. Also shown in Figure 7 is a recording of the contralateral $\mathrm{MCN1}_{\mathrm{SNAX}}$, showing the IPSPs produced by the LG action potentials in these neurons within the STG. This dual recording of both $\mathrm{MCN} 1$ neurons also shows that $\mathrm{MCN} 1$ activity had no direct influence on the contralateral MCN1 in the STG.

\section{Local control of MCNI in the STG}

In order to determine whether LG could locally control MCN1 activity within the STG when MCNl action potentials were initiated in the $\mathrm{CoG}$, we again used simultaneous recordings 

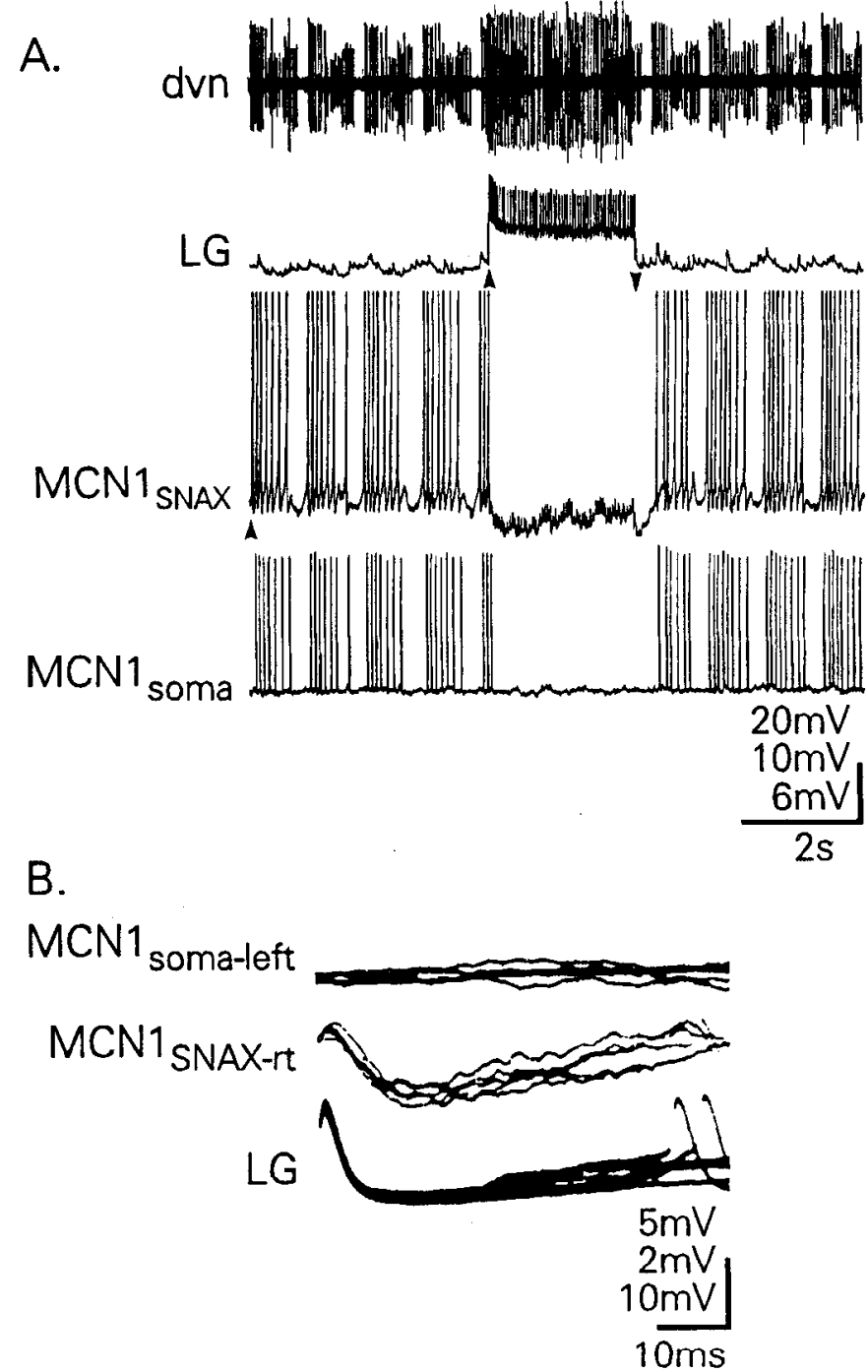

Figure 6. Synaptic inputs onto $\mathrm{MCN}_{\mathrm{SNAX}}$ are not recorded in $\mathrm{MCN}_{\text {soma }} . A, \mathrm{MCN} 1$ spikes were initiated at the STG by constantamplitude depolarizing current injection into $\mathrm{MCN1}_{\mathrm{SNAx}}$ (arrowhead), which then propagated to the $\mathrm{MCN} 1_{\text {soma }}$ recording site. During $M C N 1_{\mathrm{SNAx}}$ depolarization, LG was stimulated (between arrowheads; firing frequency, $24 \mathrm{~Hz}$ ). The IPSPs from LG onto MCN1 $1_{\text {SNAx }}$ were not seen at the $\mathrm{MCN1}_{\text {soma }}$ recording site. MCN1 activity was time locked to the pyloric rhythm $(d v n)$. MCN1 $1_{\text {SNAx }}$ stimulation began prior to the start of this figure, and persisted for the duration of the figure. LG neuron activity is also seen as the largest-amplitude spikes in the $d v n$ recording. Membrane potentials: $M C N I_{\text {soma }},-56 \mathrm{mV} ; L G,-60 \mathrm{mV} . B$, Superimposed oscilloscope sweeps triggered by impulses elicited in LG show that each LG action potential produced an EPSP followed by an IPSP in $M C N 1_{\mathrm{SNAX}-n}$ but produced no response in MCN1 $1_{\text {soma-ent }}$. The EPSP results from electrical coupling between LG and MCN1 $1_{\text {SNAX }}$ (Nusbaum et al., 1992b). Membrane potentials: $M C N I_{S N A X},-45 \mathrm{mV} ; M C N I_{\text {soma }},-60 \mathrm{mV}$. $A$ and $B$ are from different preparations.

from $M C N 1_{\text {SNAX }}, M C N 1_{\text {soma }}$, and LG. In this case, we stimulated LG while maintaining impulse activity in $\mathrm{MCN} 1_{\text {soma }}$ with constant-amplitude depolarizing current injection (Fig. 8). Although, as expected, LG did produce a hyperpolarization of the $M C N 1_{\text {SNAX }}$ membrane potential, this hyperpolarization did not inhibit the $M C N 1_{\text {soma }}$-elicited action potentials at the $M C N 1_{\text {SNAX }}$ recording site. However, if the conductance increase underlying the LG inhibition of MCN1 in the STG neuropil would have been effective at the $M C N 1_{\text {SNAX }}$ recording site, then it would have at least decreased the amplitude of the $\mathrm{MCN}_{1}{ }_{\text {soma }}$ action

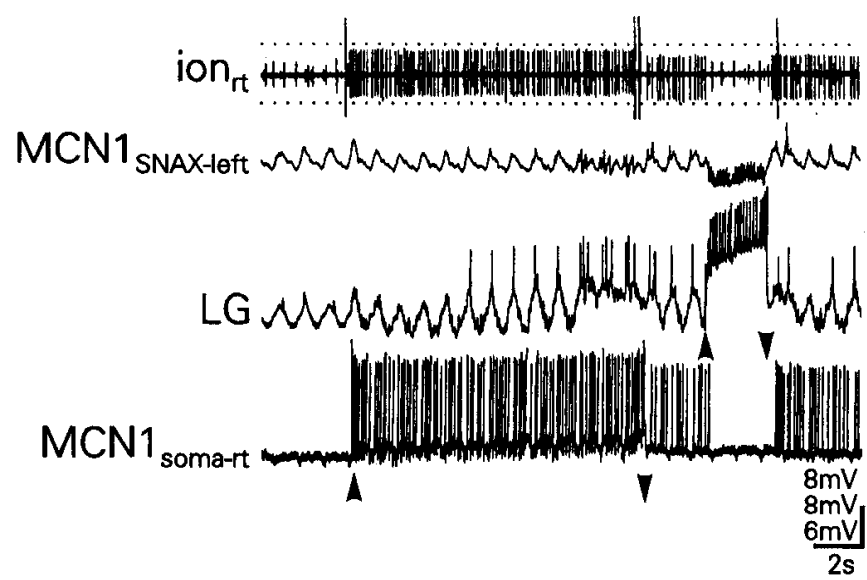

Figure 7. LG neuron activity suppresses MCN1 spikes initiated in the STG. Intracellular stimulation of $\mathrm{MCN1}_{\text {soma-r }}$ (between arrowheads; firing frequency, $10 \mathrm{~Hz}$ ) increased the pyloric-timed oscillations in the LG neuron. Following termination of $\mathrm{MCN1}_{\text {soma-r }}$ stimulation, $\mathrm{MCNl}_{\mathrm{n}}$ activity persisted but the direction of impulse propagation was reversed (note change in shape of MCN1 spikes in the ion $_{\mathrm{rt}}$ recording). During this time, LG was stimulated (arrowheads; firing frequency, $10 \mathrm{~Hz}$ ), causing an inhibition in $M C N 1_{n}$ activity. Note also that during $L G$ activity, IPSPs appeared in the contralateral $\mathrm{MCN1}_{\mathrm{SNAX} \text {-leff }}$ and $\mathrm{MCN1}_{\mathrm{rt}}$ spikes no longer appeared in the ion $_{\mathrm{r}}$. After LG stimulation ended, activity resumed in $\mathrm{MCN}_{\mathrm{r}}$. Membrane potentials: $M C N 1_{\text {soma.r. }},-56$ $\mathrm{mV} ; L G,-45 \mathrm{mV}$ to $-50 \mathrm{mV}$ (peak to trough of slow wave); $M C N 1_{S N A X-\text { leff }}$, -58 to $-62 \mathrm{mV}$ (peak to trough of slow wave).

potentials at the $\mathrm{MCN} 1_{\mathrm{SNAX}}$ recording site, if not completely suppressed them. As is evident in Figure 8, the synaptic inhibition from LG instead appeared to be only passively spread from the STG neuropil to the $M C N 1_{\mathrm{SNAx}}$ recording site, since the MCN1 action potentials were slightly larger in amplitude during the IPSP barrage. Although not yet documented, the synaptic inhibition from LG to MCN1 $1_{\text {SNAX }}$ is likely to result from a conductance increase since (1) it inhibits $\mathrm{MCN}_{\mathrm{SNAX}^{-}}$ initiated spikes, (2) its reversal potential is between $-60 \mathrm{mV}$ and $-65 \mathrm{mV}$ (P. Meyrand, M. J. Coleman, and M. P. Nusbaum, unpublished observations), and (3) it is reversibly suppressed by picrotoxin $\left(10^{-5} \mathrm{M}\right.$; Meyrand et al., unpublished observations). LG is glutamatergic and in crab STG neurons glutamate inhibition produces picrotoxin-sensitive increases in either chloride or potassium conductance (Marder and Paupardin-Tritsch, 1978; Marder, 1987).

The inability of LG activity to inhibit the $\mathrm{MCN}_{\mathrm{soma}}$-elicited spikes at $M C N 1_{\text {SNAX }}$ was not due to synaptic fatigue, because several seconds later the LG neuron was able to inhibit MCNI spikes initiated at the STG (Fig. 8). As was the case in Figure 7 , the STG spike initiation zone of MCN1 became active after $M C N 1_{\text {soma }}$ stimulation was terminated. This switch in the site of MCN1 spike initiation is evident in the ion recording (see also Fig. 7).

Despite the fact that $\mathrm{LG}$ activity did not inhibit $\mathrm{MCN}_{\text {soma }}$ elicited spikes at the $M C N 1_{\text {SNAX }}$ recording site, it appeared likely that the LG neuron was, indeed, interfering with these MCN1 spikes after they passed the $\mathrm{MCN} 1_{\mathrm{SNAx}}$ recording site and entered the STG neuropil. To test this hypothesis, we uscd the excitatory response of the DG neuron as an assay of $\mathrm{MCN} 1$ activity within the STG (Fig. 9). We chose the DG neuron because, while MCN1 also excites many other STG neurons, the DG neuron was one of the few STG targets of MCN1 that was neither inhibited by LG, strongly electrically coupled to 


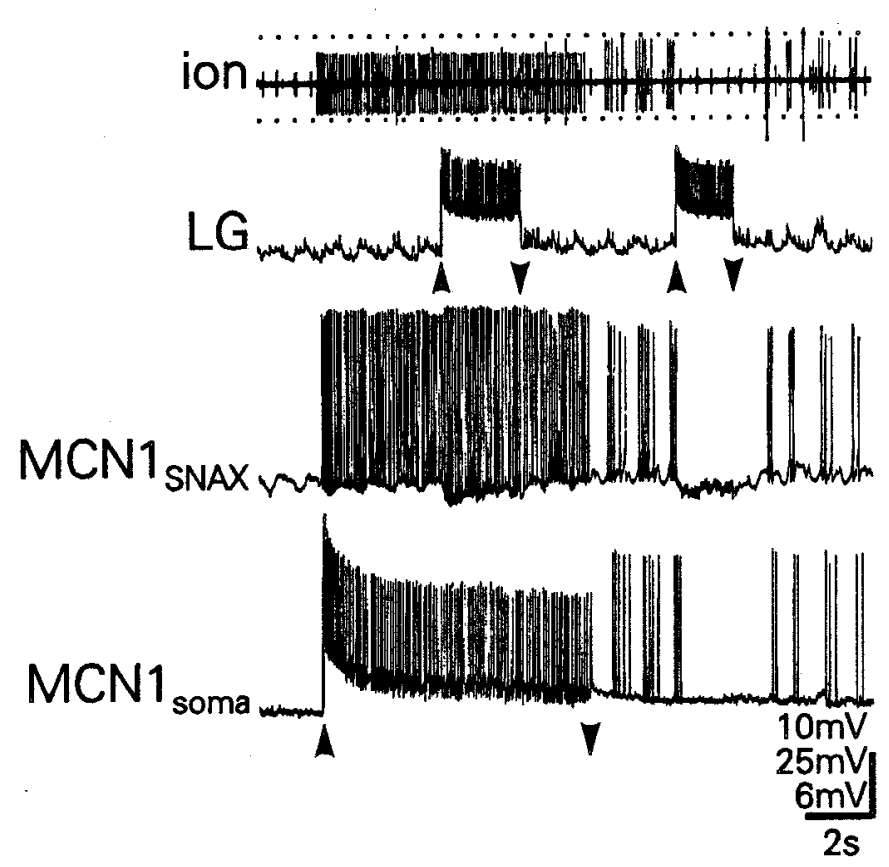

Figure 8. LG does not inhibit $\mathrm{MCN}_{\mathrm{soma}}$-elicited action potentials in either the $\mathrm{CoG}$ or at the $\mathrm{MCN}_{\mathrm{SNAX}}$ recording site. During depolarizing current injection into $\mathrm{MCN1}_{\text {soma }}$ (between arrowheads), LG stimulation (between arrowheads) did not inhibit $\mathrm{MCN}_{\text {soma }}$ spikes at either $\mathrm{MCN1}$ recording site. $\mathrm{LG}$ activity, however, did hyperpolarize $\mathrm{MCN} 1_{\mathrm{SNAx}}$. MCN1 activity persisted following $M C N 1_{\text {soma }}$ stimulation, but this latter activity originated at the STG (note change in shape of MCN1 impulses in the ion). The STG-originating spikes in MCN1 were inhibited by LG stimulation (arrowheads). Note the similar hyperpolarization of the MCN1 $1_{\text {SNAX }}$ membrane potential during both LG stimulations. During intracellular stimulation, the MCN1 firing frequency was $14 \mathrm{~Hz}$ while the LG firing frequency was $24 \mathrm{~Hz}$. Membrane potentials: $M C N I_{\text {soma }}$ $-56 \mathrm{mV} ; M C N 1_{S N A X},-44 \mathrm{mV}$ to $-50 \mathrm{mV}$ (peak to trough of slow wave); $L G,-60 \mathrm{mV}$.

either LG or $M C N 1_{\mathrm{SNAx}}$, nor strongly influenced by any other STG neuron (Nusbaum et al., 1992b; Coleman and Nusbaum, unpublished observations).

If LG did inhibit the effects of $M C N 1_{\text {soma }}$-elicited spikes within the STG, then this inhibition would reduce the MCN1 excitation of DG (Fig. 9). Not only should the $\mathrm{MCN} 1_{\text {soma }}$-elicited excitation of DG be reduced when $L G$ is active, but it should be increased when LG is not active. As shown in Figures 10 and 11, this is indeed the case. In Figure $10 A, M C N 1$ soma stimulation excited DG and increased the amplitude of the pyloric-timed oscillations in LG. LG was then depolarized during the $\mathrm{MCN} 1_{\text {soma }}$ stimulation and, while $\mathrm{MCN}_{\text {soma }}$ activity continued, the DG neuron stopped firing until LG stimulation was terminated. This ability of LG to control the MCN1 $1_{\text {soma }}$ excitation of DG was routinely observed $(n=23)$. This effect appeared to result from the LG inhibition of the MCN1 terminals within the STG, because when MCN1 $1_{\text {suma }}$ was not active, $L$ I stimulation did not inhibit DG activity (Fig. 10B). In addition, when LG activity was suppressed by hyperpolarizing current injection, $M C N 1_{\text {soma }}$ stimulation caused a stronger excitation of DG than when LG was active (Fig. 11). Thus, LG neuron activity does inhibit the effects of MCN $1_{\text {soma }}$-elicited activity within the STG.

The IPSPs produced by $\mathrm{LG}$ in $M C N 1_{\mathrm{SNAx}}$ provided a mechanism for the LG inhibition of the effects of $M C N 1_{\text {soma }}$-elicited activity within the STG. It remained possible, however, that the ability of LG to interfere with $\mathrm{MCN1}_{\text {soma }}$ effects in the STG was at least partly the result of a postsynaptic, instead of a

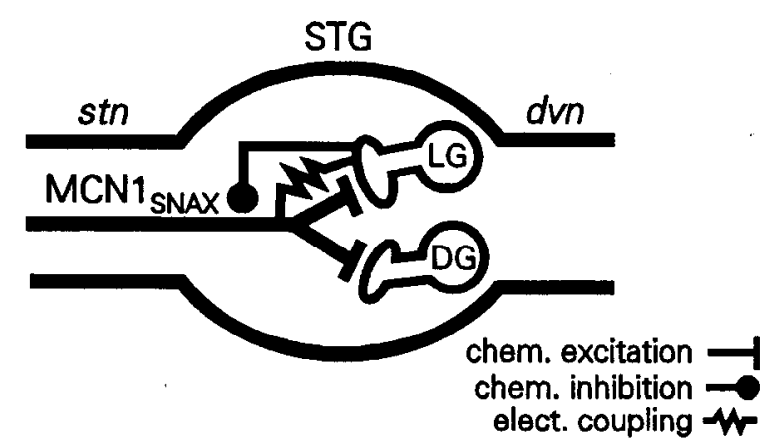

Figure 9. Schematic illustration of synaptic interactions within the STG neuropil of MCN1 and gastric mill neurons LG and DG. MCN1 excites both LG and DG, and it is also electrically coupled to LG. LG inhibits MCN1. Based on data from Nusbaum et al. (1992b).

presynaptic mechanism. Specifically, perhaps one or more of the MCN 1 transmitters were enhancing the strength of the LG synapses. If this were the case, then while LG activity did not inhibit DG in normal saline, perhaps it would do so in the presence of the MCN1 transmitters. We tested this possibility by bath applying proctolin and locustatachykinin (LomTK) to the STG. MCN1 exhibits both proctolin and LomTK-like immunoreactivity (Christie et al., 1993), and bath application of either proctolin or LomTK to the crab STG excites the STG network (Marder et al., 1986; Nusbaum and Marder, 1989; Blitz

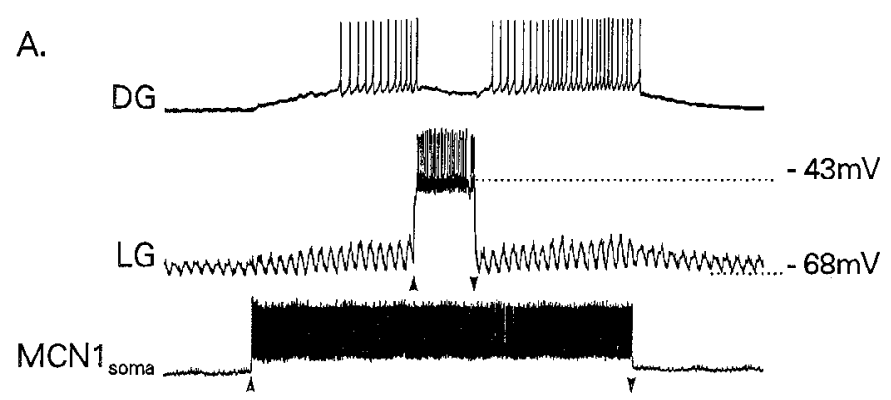

B.

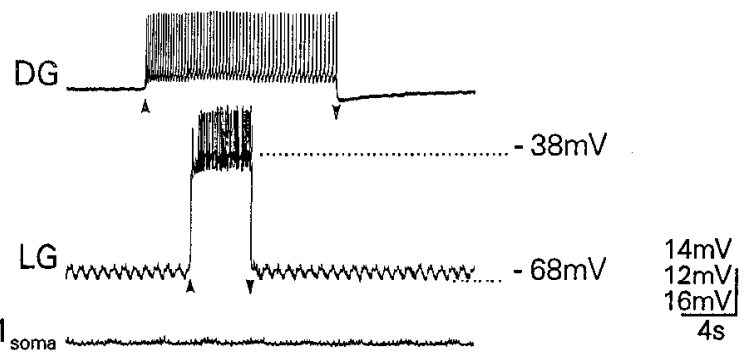

Figure 10. LG inhibits MCN1 excitation of DG within the STG. A, Intracellular stimulation of $\mathrm{MCN}_{\text {soma }}$ (arrowheads) excited the DG neuron and increased the pyloric-timed oscillations in the LG neuron. During $\mathrm{MCN}_{\text {soma }}$ stimulation, intracellular depolarization of LG (arrowheads) suppressed activity in the DG neuron. DG resumed firing after LG stimulation was terminated. LG current injection was madc via a second intracellular microelectrode (not shown). Firing frequencies during intracellular stimulation: $M C N 1,20 \mathrm{~Hz} ; L G, 11 \mathrm{~Hz} . B, L G$ has no direct inhibitory effect on DG. In the absence of MCN1 stimulation, depolarization of LG (arrowheads; firing frequency, $11 \mathrm{~Hz}$ ) that was comparable to that in $A$ did not influence DG activity. DG activity resulted from intracellular depolarizing current injection (arrowheads; $+0.9 \mathrm{nA}$ ). Membrane potentials $(A$ and $B): M C N I_{\text {soma }},-59 \mathrm{mV} ; L G$, $-68 \mathrm{mV}$ (most hyperpolarized potential); $D G,-64 \mathrm{mV}$. $A$ and $B$ are from the same recordings. 


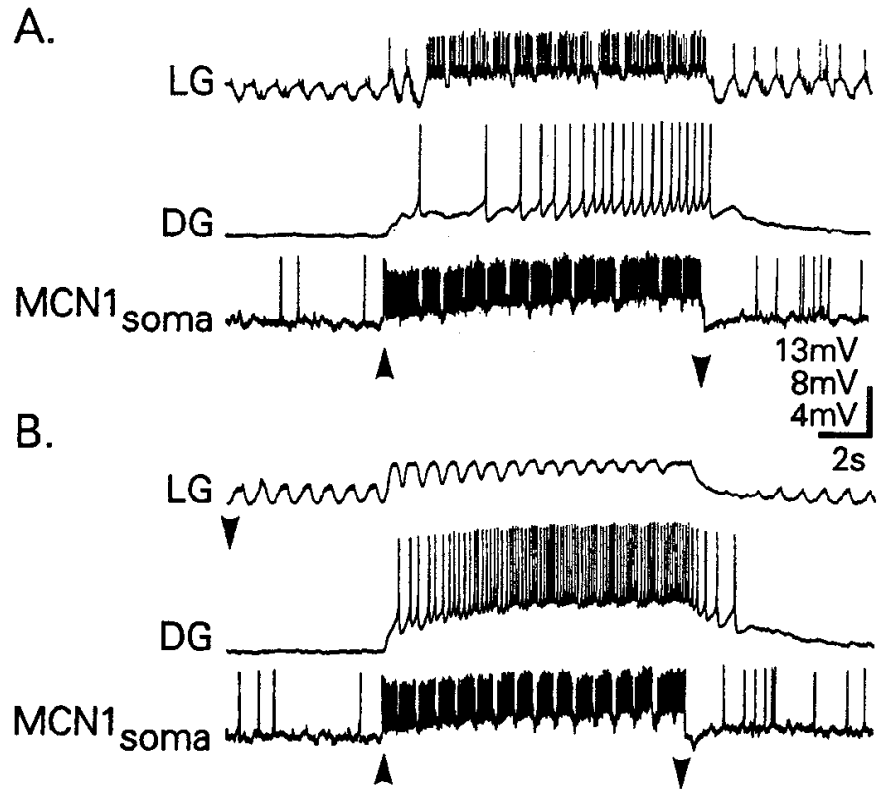

Figure 11. LG hyperpolarization enhances the excitatory effects of MCN1 on the DG neuron. $A$, Intracellular stimulation $\mathrm{MCNI}_{\text {soma }}(a r-$ rowheads; firing frequency, $30 \mathrm{~Hz}$ ) excited both LG and DG. $B$, Hyperpolarization of $L G$ (downward arrowhead; $-4 \mathrm{nA}$ ) prior to and during intracellular stimulation of $\mathrm{MCN}_{\text {soma }}$ (arrowheads; firing frequency, $33 \mathrm{~Hz}$ ) increased MCN1 excitation of DG. Membrane potentials: $M C N 1_{\text {soma }},-54 \mathrm{mV} ; D G,-72 \mathrm{mV} ; L G,-60 \mathrm{mV}$ to $-68 \mathrm{mV}$ (peak to trough of slow wave in $A$ ). $A$ and $B$ are from the same recordings.

and Nusbaum, 1993). When proctolin $\left(10^{-6} \mathrm{M}\right)$ and LomTK $\left(10^{-6} \mathrm{M}\right)$ were applied either alone or in combination to the STG, however, there was still no inhibitory effect of LG onto DG $(n=6)$.

\section{Functional significance of presynaptic inhibition of MCN1 in the $S T G$}

Since LG activity interfered with the ability of MCN1 to excite the DG neuron, we considered the possibility that the LG-mediated synaptic inhibition of $M C N 1_{\text {SNAX }}$ controlled the relative timing of the impulse bursts in the LG and DG neurons during MCN1-elicited gastric mill rhythms. In the crab STG, there is no known synaptic pathway involving STG neurons that could otherwisc account for the alternation in LG and DG activity that occurs during these gastric mill motor patterns (Fig. 10B; Weimann, 1992; Coleman and Nusbaum, unpublished observations). To test this possibility, we manipulated $L G$ activity during $\mathrm{MCN1}_{\text {soma }}$-mediated gastric mill motor patterns $(n=5)$. We found that by either activating or suppressing activity in LG, the timing of the impulse bursts in DG was changed. For example, as shown in Figure 12, suppressing $L G$ activity during an ongoing $\mathrm{MCN}_{\text {soma }}$-elicited gastric mill rhythm enabled the DG neuron to increase the frequency of its rhythmic impulse bursts. As soon as LG was released from hyperpolarization, it fired an impulse burst and again controlled the timing of the DG activity. In contrast, when we stimulated LG during DG bursts that were occurring in MCN1-elicited gastric mill rhythms, DG activity was prematurely terminated.

\section{Discussion}

We have identified the cell body of a modulatory projection neuron, MCN1, studied previously via intra-axonal recordings from a site electrotonically distant from the cell body. Based on

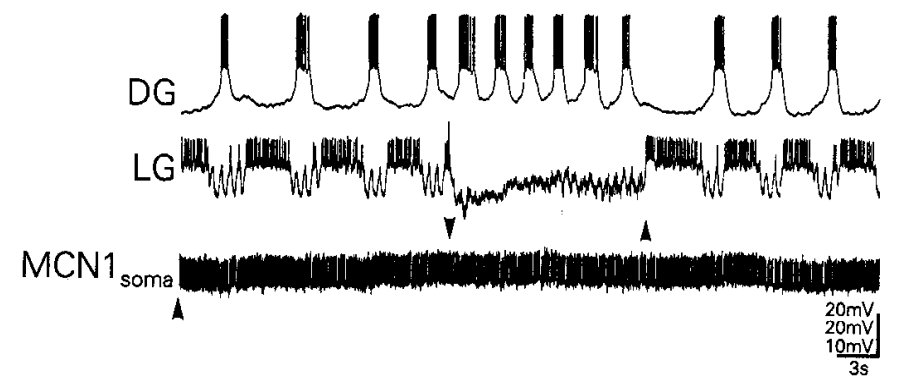

Figure 12. LG inhibition of MCN1 controls the timing of DG ncuron impulse bursts during MCN1-elicited gastric mill rhythms. Intracellular stimulation of $\mathrm{MCN}_{\text {soma }}$, which was maintained throughout the recording (arrowhead), elicited a gastric mill rhythm in which LG and DG were firing impulse bursts in alternation. When LG was hyperpolarized by intracellular current injection (arrowheads; $-3 \mathrm{nA}$ ), there was an increase in the frequency of the rhythmic bursts in the DG neuron. The frequency of the DG bursts was slowed as soon as hyperpolarization was removed from LG, and DG activity was again time locked to that in the LG neuron. Note that there was no change in MCN1 firing frequency throughout the recording $(20 \mathrm{~Hz})$. Membrane potentials: $L G$, $-56 \mathrm{mV}$ to $-68 \mathrm{mV}$ (peak to trough of slow wave); $D G,-47 \mathrm{mV}$ to $-67 \mathrm{mV}$ (peak to trough of slow wave).

both anatomical and electrophysiological data, MCN1 is likely to be the Cancer borealis equivalent to the $\mathbf{P}$ neuron, identified previously via intrasomatic recordings in both the spiny lobster, Panulirus interruptus (Selverston et al., 1976), and the European lobster, Homarus gammarus (Cardi and Nagy, 1994; Nagy and Cardi, 1994; Nagy et al., 1994). There is insufficient information available regarding the $P$ neuron in the spiny lobster for a direct comparison. The $\mathrm{P}$ neuron in the European lobster does share with MCN1 at least some of the same characteristics, including its axonal projection pattern, its pyloric-timed activity in the $\mathrm{CoG}$, and its ability to excite the pyloric motor pattern. The pyloric-timed activity in the $P$ neuron results at least partly from activity in the anterior burster (AB) ncuron, which projects to the CoG from the STG and inhibits the P neuron (Selverston et al., 1976; Nagy et al., 1994). We have shown that the pylorictimed inhibitory input to $\mathrm{MCN} 1$ in the $\mathrm{CoG}$ also originates from the STG and occurs during the time of $A B$ neuron activity, because the $A B$ and $P D$ neurons are coactive during pyloric rhythms and PD does not project to the CoG. Thus far, the $P$ neuron influence on the gastric mill system has not been examined, and while the $\mathrm{P}$ neuron and MCN1 both provide modulatory excitation to the pyloric rhythm, the MCN1 influence on the pyloric rhythm has not yet been studied as extensively as has been done for the $\mathrm{P}$ neuron.

\section{Flexibility in neural network output}

Previous studies in many systems, including the STNS, have shown that modulatory inputs impart considerable flexibility to neural network output (Harris-Warrick and Marder, 1991; Harris-Warrick et al., 1992a; Pearson and Ramirez, 1992; Steriade et al., 1993). This usually results from modulation of the membrane properties and/or synaptic strengths of network neurons. In the case of the crab gastric mill rhythm, another mechanism underlying the flexibility in motor pattern production results from the ability of some projection neurons also to provide timing cues that help determine the form of the motor pattern. Thus, one consequence of the lack of synaptic connections between LG and DG is that the timing of their activity patterns relative to each other depends on extrinsic input. For example, 
in contrast to their pattern of alternating impulse bursts during MCN1-elicited gastric mill rhythms, these two neurons burst together during a distinct form of the gastric mill rhythm that occurs with activation of modulatory commissural neuron 7 (MCN7; Coleman et al., 1993). LG and DG can also exhibit alternating impulse bursts during a third form of the gastric mill rhythm that involves activation of modulatory commissural neuron 2 (MCN2: Norris et al., 1993). When MCN2 exhibits gastric mill-timed bursts, it excites $L G$ and, independent of $L G$ activity, inhibits DG. This constrains DG to fire in alternation with LG. This means of controlling the timing of the LG and DG bursts during gastric mill rhythms in Cancer is distinct from that occurring in the lobster $P$. interruptus, where there are reciprocal inhibitory connections between these two gastric mill neurons (Mulloney, 1987; Elson and Selverston, 1992).

\section{Functional compartmentalization of neuronal activity}

We have found there to be a functional compartmentalization of $\mathrm{MCN} 1$ during $\mathrm{MCN}_{\text {soma }}$-elicited gastric mill motor patterns. This compartmentalization results from local synaptic inputs onto the MCNI terminals in the STG. Thus, during times when the gastric mill rhythm is elicited by maintained $\mathrm{MCN}_{\text {soma }}$ activity, LG neuron impulse bursts rhythmically inhibit the MCN1 effects within the STG neuropil.

Nusbaum et al. (1992b) showed that LG suppresses MCN 1 spike initiation within the STG. In this article, we found that LG also interferes with MCN1 spikes that are initiated in the $\mathrm{CoG}$ and propagate to the STG. However, because our $\mathrm{MCN} 1_{\text {SNAX }}$ recordings were outside of the STG neuropil, we were not able to determine whether the $\mathrm{LG}$ inhibition of the $\mathrm{MCN} 1_{\text {soma }}$ effects in the STG resulted from its elimination of the MCN1 action potentials or by reducing their amplitude to a level that was ineffective in mediating transmitter release. In either case, there are several lines of evidence that suggest that the $\mathrm{MCN} 1_{\text {soma }}$ spike only spreads passively into the STG neuropil. If this is indeed the case for MCN1, then it would increase the effectiveness of the LG inhibition, since passively spread spikes are more susceptible to inhibition than are actively propagated ones (Segev, 1990). Supporting this possibility is the fact that the spikes of all pyloric and gastric mill STG neurons spread passively into the STG (Mulloney and Selverston, 1972; Raper, 1979; Meyrand et al., 1992). Additionally, in another crustacean preparation, intra-axonal rccordings from the central projections of primary afferents within the thoracic ganglion indicate that the spikes in these neurons also spread passively once they enter the ganglion (Cattaert et al., 1992). Cattaert et al. (1992) also showed that the passively spread spikes in crayfish sensory neurons are reduced in amplitude by presynaptic inhibition, resulting in a decrease in the amplitude of the PSPs that they evoke in their target neurons. Thus, even if the LG inhibition only reduces the amplitude of the MCN1 spikes, this could still be sufficient to reduce or eliminate the postsynaptic effects of MCN1. This is further supported by the fact that the ability of the passively spread spikes of STG neurons to evoke PSPs within the ganglion is determined by the level of the underlying membrane potential (Meyrand et al., 1992).

As suggested by Chiel et al. (1988), in neurons where the spike initiation zone is close to the release sites of that neuron, the distinction betwcen pre- and postsynaptic inhibition becomes blurred. This is the case for $\mathrm{LG}$ inhibition of $\mathrm{MCN} 1$, where there is postsynaptic inhibition of MCN1 spikes initiated in the STG, and presynaptic inhibition of its STG release sites. In terms of $\mathrm{MCN1}_{\text {soma }}$-initiated spikes that propagate to the STG to evoke transmitter release, $L G$ inhibition is presynaptic only.

It was not surprising that we did not observe an inhibition of the $M C N 1_{\text {soma }}$ spikes at $M C N 1_{\text {SNAX }}$ since this recording site preceded the site of synaptic inhibition. A previous ultrastructural study by King $(1976 a, b)$ showed that all synaptic interactions in the STG occur within the neuropil. In a modeling study of presynaptic inhibition, Segev (1990) showed that presynaptic inhibition onto neuropil terminals would not be effective at a recording site that was as close as a few tenths of a space constant away from the site of inhibition. Although we have not determined the $\mathrm{MCN} 1$ space constant, the $\mathrm{MCN}_{\text {SNAX }}$ recording site was sufficiently distant from the site of $L G$ inhibition that the IPSPs appeared to be only passively spread to this recording site.

It remains unclear why $\mathrm{MCN} 1$ receives rhythmic input from the STG network onto its terminals in both the CoG and the STG. While the pyloric-timed input to MCN1 results in the same pattern in both ganglia, the gastric mill-timed input is quite different. During LG impulse bursts, $M C N 1_{\mathrm{SNAX}}$ is inhihited but $\mathrm{MCN}_{\text {soma }}$ actually shows slightly increased activity. Presumably, the purpose of the spatially separated inputs onto $\mathrm{MCN} 1$ pertains to its functions in each ganglion. For example, while LG is suppressing MCN1 actions in the STG, it may be appropriate for MCN1 to continue synaptically influencing targets in the CoG. The spatially separate inputs onto MCN1 may also relate to the ability of MCN1 to initiate action potentials at either the CoG or the STG. These separate inputs would ensure that MCN1 activity would be correctly timed, regardless of which end of the neuron was initiating activity.

In conclusion, our results indicate that the neuronal activity recorded intrasomatically does not necessarily reflect the activity pattern of the recorded neuron at electrotonically distant sites. Such a functional compartmentalization increases the complexity of neuronal signaling without necessitating an increase in the number of interacting neurons.

\section{References}

Beltz B, Kravitz EA (1983) Mapping of serotonin-like immunoreactivity in the lobster nervous system. J Neurosci 3:585-602.

Blitz DM, Nusbaum MP (1993) Modulation of pyloric network activity by two families of tachykinin-like peptides. Soc Neurosci Abstr 19:931.

Brodfuehrer PD, Friesen WO (1986a) Initiation of swimming activity by trigger neurons in the leech subesophageal ganglion. J Comp Physiol [A] 159:489-502.

Brodfuehrer PD, Friesen WO (1986b) Initiation of swimming activity by trigger neurons in the leech subesophageal ganglion. III. Sensory inputs to Tr1 and Tr2. J Comp Physiol [A] 159:511-519.

Cardi P, Nagy F (1994) A rhythmic modulatory gating system in the stomatogastric nervous system of Homarus gammarus. III. Rhythmic control of the pyloric CPG. J Neurophysiol, in press.

Cattaert D, El Manira A, Clarac F (1992) Direct evidence for presynaptic inhibitory mechanisms in crayfish sensory afferents. J Neurophysiol 67:610-624.

Chiel HJ, Kupfermann I, Weiss KR (1988) An identified histaminergic neuron can modulate the outputs of buccal-cerebral interneurons in Aplysia via presynaptic inhibition. J Neurosci 8:49-63.

Christie AE, Norris BJ, Coleman MJ, Marder E, Nusbaum MP (1993) Neuropil arborization and transmitter complement of a modulatory projection neuron. Soc Neurosci Abstr 19:931.

Clarac F, El Manira A, Cattaert D (1992) Presynaptic control as a mechanism of sensory-motor integration. Curr Opin Neurobiol 2:764769.

Coleman MJ, Nusbaum MP (1992) An identified modulatory neuron exhibits different activity patterns in spatially separate arbors. Soc Neurosci Abstr 18:1279. 
Coleman MJ, Nusbaum MP, Cournil I, Claiborne BJ (1992) Distribution of modulatory inputs to the stomatogastric ganglion of the crab, Cancer borealis. J Comp Neurol 325:581-594.

Coleman MJ, Norris BJ, Nusbaum MP (1993) Functional modification of rhythmic motor activity by a modulatory projection neuron. Soc Neurosci Abstr 19:1701.

Elson RC, Selverston AI (1992) Mechanisms of gastric rhythm generation in the isolated stomatogastric ganglion of spiny lobsters: bursting pacemaker potentials, synaptic interactions and muscarinic modulation. J Neurophysiol 68:890-907.

Glantz RM, Wang-Bennett L, Waldrop B (1985) Presynaptic inhibition in the crayfish brain. I. Inhibition of a central synapse and synaptic crents in presynaptic terminals. J Comp Physiol 156:477-487.

Grillner S, Matsushima T (1991) The neural network underlying locomotion in lamprey-synaptic and cellular mechanisms. Neuron 7:115.

Harris-Warrick RM, Marder E (1991) Modulation of neural networks for behavior. Annu Rev Neurosci 14:39-57.

Harris-Warrick RM, Marder E, Selverston AI, Moulins M, eds (1992a) Dynamic biological networks: the stomatogastric nervous system. Cambridge, MA: MIT Press.

Harris-Warrick RM, Nagy F, Nusbaum MP (1992b) Neuromodulation of stomatogastric networks by identified neurons and transmitters. In: Dynamic biological networks: the stomatogastric nervous system (Harris-Warrick RM, Marder E, Selverston AI, Moulins M, eds), pp 87-138. Cambridge, MA: MIT Press.

Haydon PG, Winlow W (1982) Multipolar ncuroncs in Lymnaea stagnalis. I. Multiple spike initiation sites and propagation failure allow neuronal compartmentalization. J Comp Physiol 147:503-510.

Hounsgaard J, Kiehn O (1993) Calcium spikes and calcium plateaux evoked by differential polarization in dendrites of turtle motoneurones in vitro. J Physiol (Lond) 468:245-259.

King DG (1976a) Organization of crustacean neuropil. I. Patterns of synaptic connections in lobster stomatogastric ganglion. J Neurocytol 5:207-237.

King DG (1976b) Organization of crustacean neuropil. II. Distribution of synaptic contacts on identified motor neurons in lobster stomatogastric ganglion. J Neurocytol 5:239-266.

Marder E (1987) Neurotransmitters and neuromodulators. In: The crustacean stomatogastric system (Selverston AI, Moulins M, eds), pp 263-300. Berlin: Springer.

Marder E, Paupardin-Tritsch D (1978) The pharmacological properties of some crustacean neuronal acetylcholine, gamma-aminobutyric acid, and L-glutamate responses. J Physiol (Lond) 280:213-236.

Marder E, Weimann JM (1992) Modulatory control of multiple task processing in the stomatogastric nervous system. In: Neurobiology of motor programme selection: new approaches to mechanisms of behavioral choice (Kien J, McCrohan C, Winlow W, eds), pp 3-19. Manchester: Manchester UP.

Marder E, Hooper SL, Siwicki KK (1986) Modulatory action and distribution of the neuropeptide proctolin in the crustacean stomatogastric nervous system. J Comp Neurol 234:454-467.

McCrohan CR (1988) Modification of central pattern generation in invertebrates. Comp Biochem Physiol [A] 90:17-22.

Meyrand P, Weimann JM, Marder E (1992) Multiplc axonal spikc initiation zones in a motor neuron: serotonin activation. $J$ Neurosci $12: 2803-2812$

Mulloney B (1987) Neural circuits. In: The crustacean stomatogastric system (Selverston AI, Moulins M, eds), pp 57-77. Berlin: Springer.

Mulloney B, Selverston AI (1972) Antidromic action potentials fail to demonstrate known interactions between neurons. Science 177: 69-72.

Nagy F, Cardi P (1994) A rhythmic modulatory gating system in the stomatogastric nervous system of Homarus gammarus. II. Modulatory control of the pyloric CPG. J Neurophysiol, in press.

Nagy F, Dickinson PS, Moulins M (1981) Rhythmical synaptic control of axonal conduction in a lobster motor neuron. J Neurophysiol 45: 1109-1124.
Nagy F, Cardi P, Cournil I (1994) A rhythmic modulatory gating system in the stomatogastric nervous system of Homarus gammarus. I. Pyloric-related neurons in the commissural ganglia. J Neurophysiol, in press.

Nelson R, Lutzow AV, Kolb H, Couras P (1975) Horizontal cells in the cat retina with independent dendritic systems. Science 189:137139

Norris BJ, Coleman MJ, Nusbaum MP (1993) Modification of rhythmic motor activity by recruitment of a newly identified modulatory projection neuron. Soc Neurosci Abstr 19:1701.

Nusbaum MP, Marder E (1989) A modulatory proctolin-containing neuron (MPN). II. State-dependent modulation of rhythmic motor activity. J Neurosci 9:1600-1607.

Nusbaum MP, Coleman MJ, Norris BJ (1992a) Selective enhancement of rhythmic pacemaker ensemble activity by a newly identified modulatory neuron. Soc Neurosci Abstr 18:1056.

Nusbaum MP, Weimann JM, Golowasch J, Marder E (1992b) Presynaptic control of modulatory fibers by their neural network targets. J Neurosci 12:2706-2714.

Oland LA, Stuart AE, Hayashi JH, Callaway JC (1987) Voltage spread in an identified interneuron of the barnacle's visual system. J Neurophysiol 58:1420-1430.

Pearson KG, Ramirez J-M (1992) Parallels with other invertebrate and vertebrate motor systems. In: Dynamic biological networks: the stomatogastric nervous system (Harris-Warrick RM, Marder E, Selverston AI, Moulins M, eds), pp 263-281. Cambridge, MA: MIT Press.

Perreault M-C, Drew T, Rossignol S (1993) Activity of medullary reticulospinal neurons during fictive locomotion. J Neurophysiol 69: 2232-2247.

Raper JA (1979) Nonimpulse-mediated synaptic transmission during the generation of a cyclic motor program. Science 205:304-306.

Robertson RM, Moulins M (1981) A corollary discharge of total foregut motor activity is monitored by a single interneurone in the lobster Homarus gammarus. J Physiol (Paris) 77:823-827.

Ross WN, Lasser-Ross N, Werman R (1990) Spatial and temporal analysis of calcium-dependent electrical activity in guinea pig Purkinje cell dendrites. Proc $R$ Soc Lond [Biol] 240:173-185.

Rudomin P, Quevedo J, Eguibar R (1993) Presynaptic modulation of spinal reflexes. Curr Opin Neurobiol 3:997-1004.

Scgev I (1990) Computer study of presynaptic inhibition controlling the spread of action potentials into axonal terminals. J Neurophysiol 63:987-998.

Selverston AI, Moulins M (1987) The crustacean stomatogastric system. Berlin: Springer.

Selverston AI, Russell DF, Miller JP, King DG (1976) The stomatogastric nervous system: structure and function of a small neural network. Prog Neurobiol 7:215-290.

Skydsgaard M, Hounsgaard J (1994) Spatial integration of local transmitter responses in motoneurones of the turtle spinal cord in vitro. $\mathbf{J}$ Physiol (Lond), in press.

Steriade M, McCormick D, Sejnowski T (1993) Thalamocortical oscillations in the sleeping and aroused brain. Science 262:679-685.

Watson AHD (1992) Presynaptic modulation of sensory afferents in the invertcbratc and vertcbrate nervous system. Comp Biochem Physiol [A] 103:227-239.

Weimann JM (1992) Multiple task processing in neural networks: numerous central pattern generators in the stomatogastric nervous system of the crab, Cancer borealis. PhD dissertation, Brandeis University.

Weimann JM, Meyrand P, Marder E (1991) Neurons that form multiple pattern generators: identification and multiple activity patterns of gastric/pyloric neurons in the crab stomatogastric system. J Neurophysiol 65:111-122.

Weimann JM, Marder E, Evans B, Calabrese RL (1993) The effects of SDRNFLRFamide and TNRNFLRFamide on the motor patterns of the stomatogastric ganglion of the crab Cancer borealis. J Exp Biol 181:1-26. 